Scientific Visualization, 2020, volume 12, number 2, pages 9 - 20, DOI: 10.26583/sv.12.2.02

\title{
Visualization of the interconnection between dynamics of the system and its basic characteristics
}

\author{
G.V. Kreinin',A, S.Yu. Misyurin²,A,B, A.P. Nelyubin3,A,B, N.Yu. Nosova4,A,B \\ A Mechanical Engineering Research Institute RAS \\ B National Research Nuclear University MEPhI \\ ${ }^{1}$ ORCID: 0ooo-0002-9515-6766, gkreynin@mail.ru \\ 2 ORCID: oooo-0003-1020-0527, symisyurin@mephi.ru \\ 3 ORCID: 0000-0002-7064-3103, nelubin@gmail.com \\ 4 ORCID: 0000-0002-1213-9312, natahys@mail.ru
}

\begin{abstract}
The paper presents a dimensionless mathematical model of the dynamics of the drive complex and the visualization of the solution of this model, which allows to obtain comparative estimates (characteristics) of the solutions obtained in the first approximation.

The authors proposed an original control system for the drive complex of two hydraulic actuators to lift the load in parallel mode. A distinctive feature is the adopted control circuit of the complex through three hydraulic switchgears, which are responsible for regulating the overall object lifting (and/or lowering) speed and maintaining the horizontal position of the object within the specified accuracy in the presence of disturbing factors of different nature. The difference in displacements of the hydraulic actuator rods from some initial (basic) position at a given time is a sign of deviation of the object from the horizontal position. The mathematical model of the object obtained is investigated in dimensionless variables, which greatly simplifies the visual synthesis of the object.
\end{abstract}

Keywords: dynamic system, hydraulic drive, synthesis, dimensionless parameters, visualization.

\section{Introduction}

Operations of controlled displacement of objects of large mass, large dimensions, complex geometry, or other characteristics that are inconvenient for practice are often encountered in technological processes. In some cases, such operations have to be performed by two or more robotic devices interacting with each other. The factor of interaction of several drive and control units significantly complicates the process of synthesis of such systems, and, moreover, the optimization of their structure and parameters, taking into account the requirements, criteria and constraints imposed on the system. Visualization of the expected solutions, especially at the initial stages of design, can be of great help here. Talking about visualization, we mean - a graphical representation of a complex of results of computer simulation of the system's dynamics in the dialogue mode. A visual analysis of the information provided makes it possible to quickly obtain visual estimates of the options and use them as source material in the subsequent stages of finding the optimal solution. As an example, in this paperwe consider the purposeful process of visualizing the dynamics of a manipulator designed to lift heavy loads. The lifting force is created by two parallel, synchronously working hydraulic actuators with a common control system. The visualization procedure was used for a preliminary assessment of the general properties of such a system and its ultimate capabilities. At the same time, the ability of the system to provide synchronous motion of the drives with the inequality of their loads, sensitivity to short-term load jumps and the impact on the process of basic parameters were studied. The problem of forming a block of criteria and constraints, including 
those that are not amenable to formalization was solved. The procedure is based on computer modeling of the system dynamics, represented by a dimensionless model, which contributes to the generalization of the data obtained.

As practice shows us, in such systems, actuators with different types of engines, but mainly with hydraulic and electric motors, are used. When moving especially heavy and bulky objects, preference is given to hydraulic motors, which are distinguished by high power density and do not require the inclusion of additional reinforcement mechanisms in the design. A number of examples of systems with parallel operating drives are given in [1-4]. However, there is little information about the methods of synthesis and optimization of the structure and parameters of such systems. To solve such problems, it is proposed to use the approaches developed by the authors based on an interactive procedure for the synthesis of dynamic systems, rationalization of their mathematical models, methods of matching the processes of dynamics and control of individual blocks, as well as the active use of similarity theory and, in particular, the analogy theory, in order to summarize the results [5-8]. In present work, this problem is solved by the example of controlling the movement of a heavy object moved by two synchronously working piston hydraulic engines. Mass load is assumed to be distributed between the engines unequally. We consider the initial stage of the synthesis of such a system, which is based on the analysis of visual images of computer modeling of its dynamics.

\section{Mathematical model of the system}

The basic mathematical model is obtained under the following conditions. The drives are hydraulic cylinders 1 and 2 of the same parameters and powered from a common source (Fig. 1). Synchronously operating drives move an object of mass $m=m_{1}+m_{2}$, where $m_{1,2}$ are the mass loads related to the drives. The law of motion is realized by controlled pressure change in the lower cavities, which are connected to a power source (with pressure $p_{M}$ ) through control valve 3 , intermediate cavity 4 (with volume $V$ ) and control valve 5 .

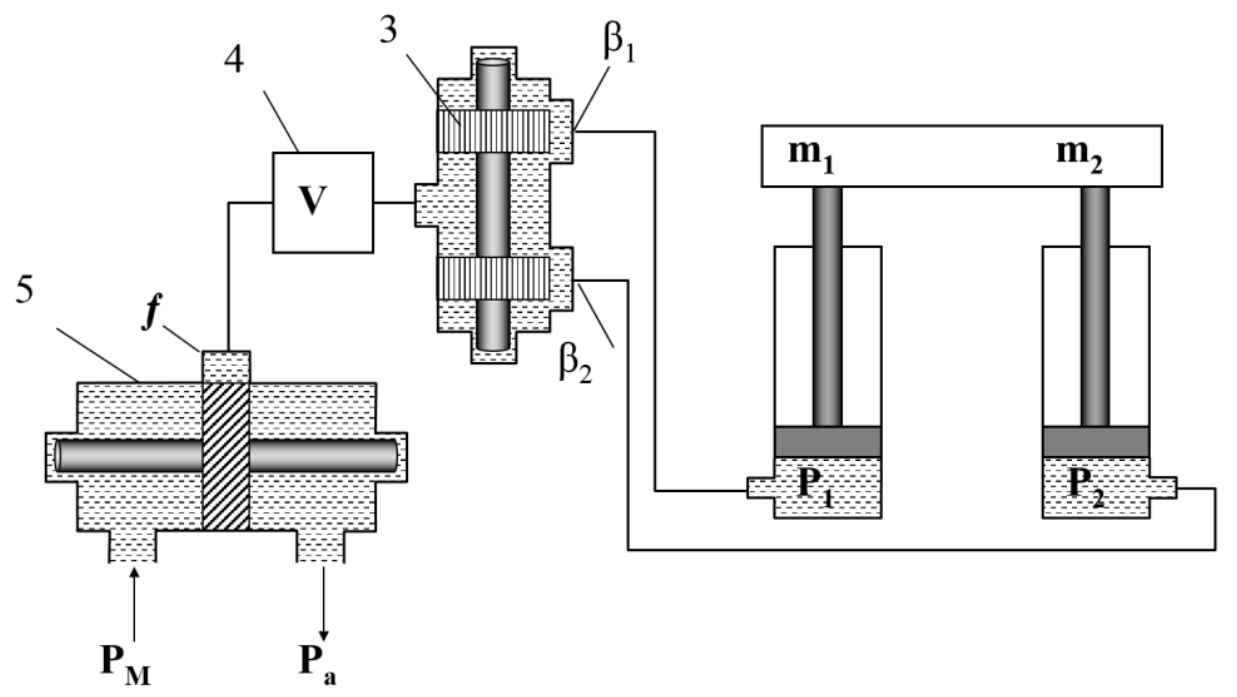

Fig. 1.

The equations of motion of the drives are:

$$
m_{1,2} \ddot{x}_{1,2}=p_{1,2} F+m_{1,2} g-k_{1,2} \dot{x}_{1,2}+P_{L 1,2},
$$

here, $x$ is piston displacement, $p$ is pressure in the lower cavity, $F$ is effective piston area, $m_{1,2} g, P_{L 1,2}$ are weight and force loads on the rod, $k_{1,2}$ are coefficients of fluid friction in the drive. 
The changes of the pressure $p_{1,2}$ in the lower cavities of the drives and the pressure $p$ in the intermediate cavity are related by dependencies:

$$
\begin{gathered}
\dot{p}=W\left(\beta \operatorname{sgn}(\Delta p) \sqrt{|\Delta p|}-\beta_{1} a_{1} \operatorname{sgn}\left(\Delta p_{1}\right) \sqrt{\left|\Delta p_{1}\right|}-\beta_{2} a_{2} \operatorname{sgn}\left(\Delta p_{2}\right) \sqrt{\left|\Delta p_{2}\right|}\right), \\
\dot{p}_{1,2}=W_{1,2}\left(\beta_{1,2} a_{1,2} \operatorname{sgn}\left(\Delta p_{1,2}\right) \sqrt{\left|\Delta p_{1,2}\right|}-\dot{x}_{1,2}\right)
\end{gathered}
$$

here, $W=\left(\mathrm{E} f / F x_{v}\right) \sqrt{\left(2 p_{M}\right) / \rho} ; W_{1,2}=\left(\mathrm{E} f / F\left(x_{01,2}+x_{1,2}\right)\right) \sqrt{\left(2 p_{M} / \rho\right.} ; \Delta p=p_{M}-p ; \Delta p_{1}=p-p_{1}$, $\Delta p_{2}=p-p_{2} ; \beta, \beta_{1}$ and $\beta_{2}$ are opening degrees of the channels $f, f_{1}$ and $f_{2}, \alpha_{1,2}=f_{1,2} / f ; \mathrm{E}$ is bulk modulus of working fluid; $x_{v}$ is the length of the intermediate cavity; $\rho$ is working fluid density.

\section{Transformation of the model into a dimensionless form}

In previous papers by the authors [5-8], it was shown that in complex, multi-parameter mechanical systems, it is recommended to use dimensionless models in which the actual parameters and other characteristics of the system are represented as dimensionless complexes. This reduces the number of basic parameters and allows us to obtain generalized characteristics, which facilitates the analysis and synthesis of the drive (mechatronic) complex. The transition to dimensionless parameters is based on the method of the analogy theory [9], equations $(1,2)$ are transformed into a dimensionless form by replacing variables with their dimensionless analogs $\lambda, \tau, \sigma$ according to the relations $x=q_{1} \lambda, t=q_{2} \tau, p=q_{3} \sigma$. As a result of this replacement, in the first approximation, as well as $m_{1,2}=c_{1,2} m, \varepsilon=\mathrm{E} / q_{3}$, and simple transformations, we obtain the transformed system (3):

$$
\begin{gathered}
c_{1,2} \ddot{\lambda}_{1,2}=\sigma_{1,2}+c_{1,2} \chi_{L}-\kappa_{1,2} \dot{\lambda}_{1,2}+\chi_{L 1,2} \\
\dot{\sigma}=K_{V}\left(\beta \operatorname{sgn}(\Delta \sigma) \sqrt{|\Delta \sigma|}-\beta_{1} \alpha_{1} \operatorname{sgn}\left(\Delta \sigma_{1}\right) \sqrt{\left.\mid \Delta \sigma_{1}\right) \mid}-\beta_{2} \alpha_{2} \operatorname{sgn}\left(\Delta \sigma_{2}\right) \sqrt{\left|\Delta \sigma_{2}\right|}\right) \\
\dot{\sigma}_{1,2}=\left(\varepsilon /\left(\lambda_{01,2}+\lambda\right)\right)\left(\beta_{1.2} \alpha_{1,2} \operatorname{sgn}\left(\Delta \sigma_{1,2}\right) \sqrt{\left|\Delta \sigma_{1,2}\right|}-\dot{\lambda}_{1,2}\right)
\end{gathered}
$$

Here, the following designations are introduced:

a) dimensionless variables: $\lambda_{1}, \lambda_{2}-$ movements of drives; $\sigma, \sigma_{1}, \sigma_{2}-$ cavity pressures; $\Delta \sigma, \Delta \sigma_{1}, \Delta \sigma_{2}$ - differential pressures between the cavities;

b) dimensionless parameters: distribution $c_{1,2}$ of mass load between drives; total mass loading of the manipulator $\chi_{L}=m g / p_{M} F$; additional resistance forces $\chi_{L 1,2}=P_{L 1,2} / p_{M} F$; stiffness of the intermediate cavity $K_{V}=\frac{\varepsilon}{\lambda_{V}}$; reduced initial volumes of actuating drives cavities $\lambda_{01,2}=x_{01,2} / q_{1}$; liquid friction forces $\kappa_{1,2}=k_{1,2} U / p_{M} F$, where $U=(f / F) \sqrt{2 p_{M} / \rho}$; the ratio between the dimensions of the flow areas of the channels $\alpha_{1,2}=f_{1,2} / f$ of the valves 3 and 5 . The initial conditions are the actual time $\tau_{S}$ of the mass $m$ movement and the magnitude $x_{S}$ of its stroke. Since the scale $q_{1}$ of measurement of dimensionless displacement is the working stroke of the manipulator, it is accepted that $q_{1}=x_{s}$. The choice of manipulator parameters is based on the results of computer modeling of the transformed systems (3) and valve control systems. 


\section{Statement of the problem of choosing manipulator pa- rameters and their optimization}

The parameters of the manipulator are selected according to the following data: the working stroke of the object; set or minimum travel time; the mass of the object being moved and the distribution of weight loads between the drives. The objects of choice are the sizes of hydraulic cylinders, the operating pressure in the hydraulic system, the flow areas of the valves and the parameters of their flow characteristics, as well as the parameters of the valve control systems.

\section{Interactive visual analysis of simulation results}

The transformed computer model (3) is used in this case to investigate a relatively little studied dynamic system with two hydraulic execution units that together solve the problem of linear movement of an object with large dimensions and mass. With the continuous interaction of the drives and the external object, quite complex mechanical and hydraulic cross-links arise, affecting the dynamics of the system. Accounting for these links is also hampered by the fact that in the course of the movement, unpredictable additional disturbances in the form of random forces of resistance, instability of parameters and other factors may arise. The nodes of the system involved in the movement are connected to each other through hydraulic and mechanical circuits, which leave some mutual freedom in the movements, which also affects the quality of the operation.

There are several methods for finding and choosing the optimal solution in the synthesis of a complex system, including methods of multicriteria optimization with the introduction of weight criteria [5, 7] or taking into account preferences. This work is devoted to the stage of data preparation for the use of these methods, for which the results of computer simulation, presented in a visual for viewing, are interactively compared [10, 11].

To present the received information in a visual form, a special program was developed using Delphi, which facilitates a visual comparison of the obtained solutions quality. The program interface is shown in Figures 2-10. In the left part of the program window are fields for entering 20 main parameters of the model. The parameters used and their designations in the program are presented in table 1 . To the right is a panel for entering the parameters of the numerical Runge-Kutta method for solving the system of equations (3). The user of the program can choose the accuracy order of the method: 2nd or 4th, and also set the grid step $h$ on the scale $x$ of the piston displacement. Here, the user can specify the control value of the parameter $x$, for which in the text box in the program window the intermediate calculation results will be displayed in numerical form. The meaning of the graphical representation of the results located on the right side of the program window will be explained later in the analysis of specific examples.

Table 1. System model parameters

\begin{tabular}{|l|l|l|l|}
\hline Designations & $\begin{array}{l}\text { Designations } \\
\text { in the pro- } \\
\text { gram }\end{array}$ & $\begin{array}{l}\text { Ranges of } \\
\text { change }\end{array}$ & Comments \\
\hline$c_{1}$ & c1 & $0,4-0,6$ & Resistance to weight imbalance drives \\
\hline$\left|\chi_{L}\right|$ & Del & $0,4-2$ & $\begin{array}{l}\text { The relative total workload on the } \\
\text { drives, which also serves as a measure } \\
\text { of their dimensions }\end{array}$ \\
\hline$\lambda_{V}$ & $0,2-1,0$ & $\begin{array}{l}\text { The measure of the volume of the in- } \\
\text { termediate chamber }\end{array}$ \\
\hline$\beta_{0}$ & beo & $0,3-0,7$ & $\begin{array}{l}\text { The share of the opening of the com- } \\
\text { mon channel in the line leading to the } \\
\text { drives that relates to the first drive. }\end{array}$ \\
\hline
\end{tabular}




\begin{tabular}{|l|l|l|l|}
\hline$\alpha_{1}$ & a1 & $0,25-1$ & $\begin{array}{l}\text { The ratio between the flow sections of } \\
\text { the common supply channel and the } \\
\text { channel leading to the first drive }\end{array}$ \\
\hline$\alpha_{2}$ & a2 & $0,25-1$ & $\begin{array}{l}\text { The same for the channel leading to } \\
\text { the second drive }\end{array}$ \\
\hline$\kappa_{1}$ & nu1 & $0,05-0,1$ & Coefficient of friction of the first drive \\
\hline$\kappa_{2}$ & nu2 & $0,05-0,1$ & $\begin{array}{l}\text { Coefficient of friction of the second } \\
\text { drive }\end{array}$ \\
\hline$\vartheta_{1}$ & $\mathrm{kd} 1$ & $25-50$ & Position feedback ratio \\
\hline$\vartheta_{2}$ & $\mathrm{kv1}$ & $0-50$ & Speed feedback ratio \\
\hline$\vartheta_{D}$ & $\mathrm{Kd}$ & $25-100$ & Position feedback ratio \\
\hline$\vartheta_{V}$ & $\mathrm{Kv}$ & $0-5$ & \begin{tabular}{l} 
Speed feedback ratio \\
\hline$\left|\chi_{L 1}\right|$
\end{tabular} \\
\hline dell1 & $0-0,1$ & $\begin{array}{l}\text { Additional short-term intermittent } \\
\text { drag force acting on the first drive }\end{array}$ \\
\hline$\left|\chi_{L 2}\right|$ & dell2 & $0-0,1$ & $\begin{array}{l}\text { Additional short-term intermittent } \\
\text { drag force acting on the second drive }\end{array}$ \\
\hline$E$ & Nux & 500 & $\begin{array}{l}\text { The dimensionless analogue of the } \\
\text { elastic modulus of a liquid (does not } \\
\text { vary) }\end{array}$ \\
\hline$\lambda_{01}$ & L1 & $0,05-1$ & $\begin{array}{l}\text { The measure of the initial (harmful) } \\
\text { volume of the first drive }\end{array}$ \\
\hline$\lambda_{02}$ & L2 & $0,05-1$ & $\begin{array}{l}\text { The measure of the initial (harmful) } \\
\text { volume of the second drive }\end{array}$ \\
\hline
\end{tabular}

Dynamics of the four system options is analyzed: 1) with the same load on the drives; 2) the first case plus additional short-term loads; 3) with unequal loads on the drives; 4) with different relative loads of the drives, which is equivalent to their different sizes.

Option 1. Fig. 2 shows the motion characteristics of the system with the same mass loads on the drives $\left(c_{1}=c_{2}\right)$ and in the absence of other power loads. In the lower part of the column a) the displacement curves and speeds of the first drive are presented, in the upper part of this column the pressures in its working cavity; in column b) there are similar indicators of the second drive. Column c) shows the channel opening curves, changes in the mismatch criterion $\Delta \lambda$ in the motion of the actuators and the pressure in the intermediate cavity above. The designations of these quantities were explained in the previous section. The curves in the subsequent figures are arranged in the same order. In addition, to the left of the graphs on each figure there is a table of the values of the parameters selected for this version of the model. The scale of the displacement $\lambda$ is doubled relative to the pressure $\sigma$. The scale in speed $\dot{\lambda}$ is ten times relative to pressure. The scale of $\beta$ (the size of the flow area) is increased five times relative to the pressure.

From the graphs it follows that in the conditions of option 1, despite the high load level of the drives $\left(\left|\chi_{\mathrm{L}}\right|=1,6\right)$, the given laws of motion of the drives are implemented with good accuracy, and the pressures after a short initial disturbance stabilizes quickly in all cavities. The functioning of the system under the conditions of option 1 is distinguished by a very low sensitivity to parameter variations within the entire selected range. 


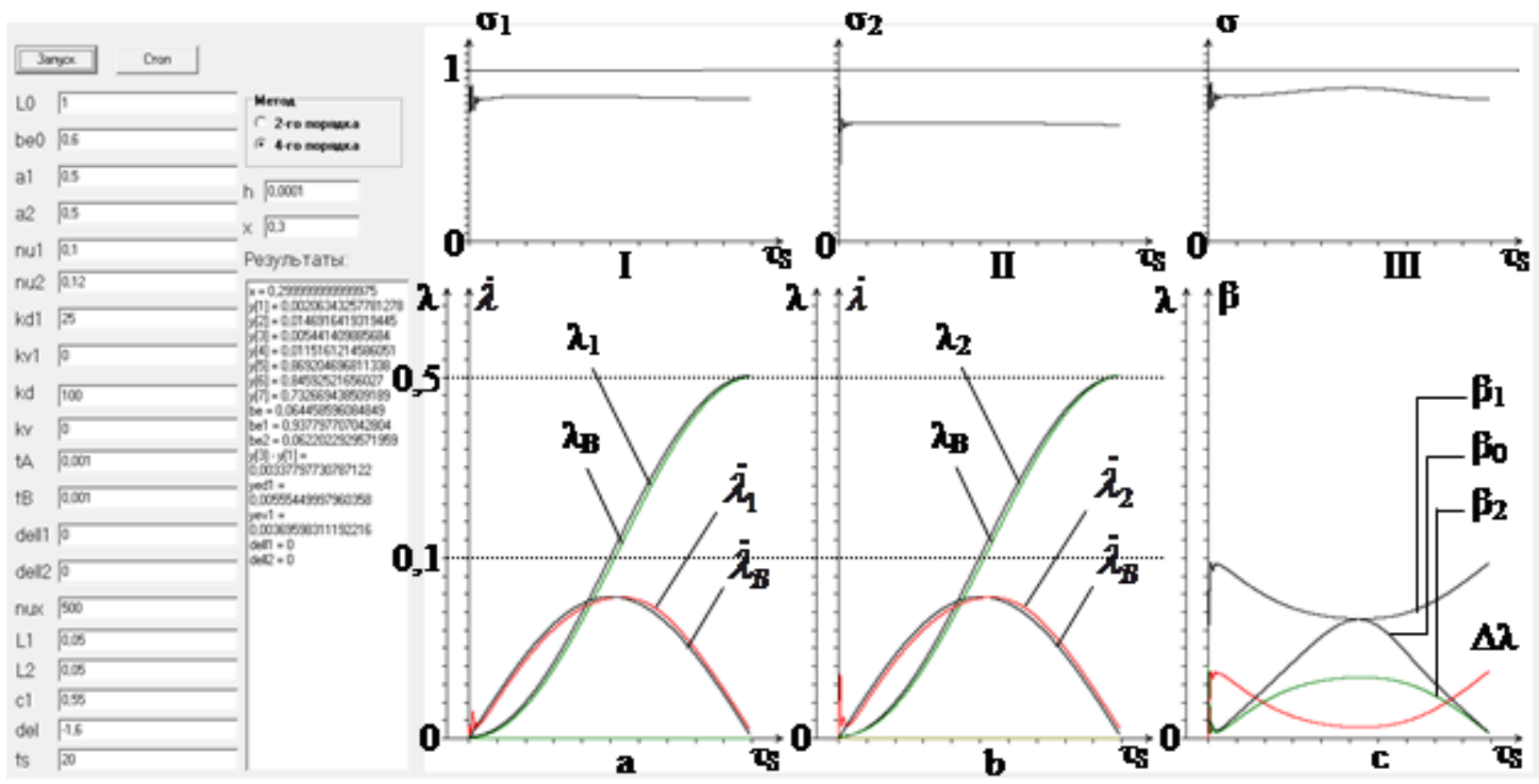

Fig. 2.

Option 2. In this option, the drives are under the additional influence of random short-term resistance forces $\left(\left|\chi_{L 1,2}\right|=0,1\right)$. The periods of their action are marked with the labels below in the graphs presented in Fig. 3. Although discontinuous perturbations influence the process, it can be seen that the process is restored after the termination of the action of the perturbations. It should be borne in mind that the results, presented in Fig. 2 and Fig. 3, are obtained under the condition that there is no imbalance of mass loads on the drives. This explains the possibility of choosing such a high value of $\left|\chi_{L}\right|=1.6$, close to the upper limit (the minimum size of the drives).

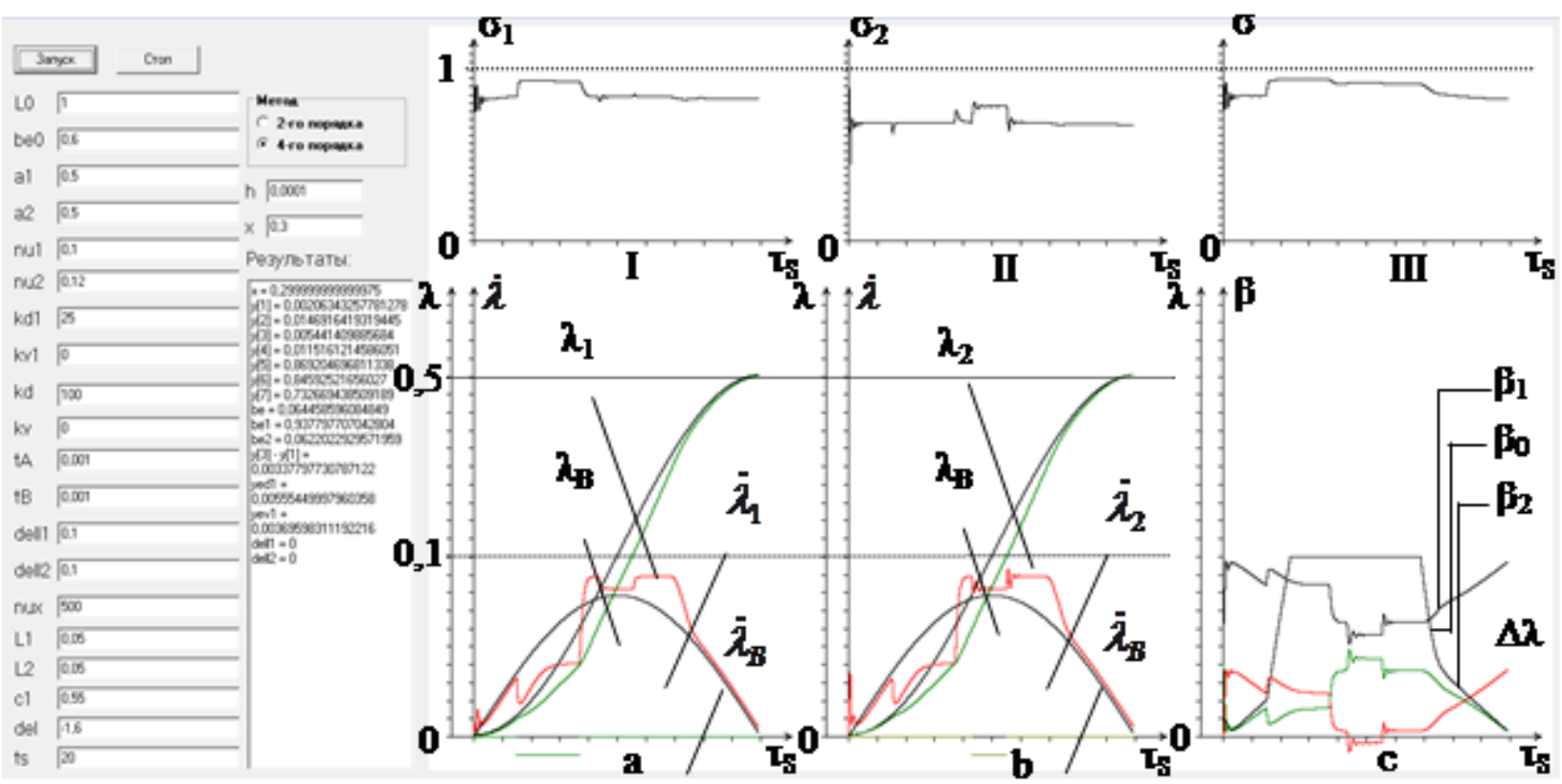

Fig. 3 .

Option 3. Imbalance of mass loads of drives $\left(c_{1} \neq c_{2}\right)$ has a significant impact on the process. The study showed that with the values of the parameters indicated in Fig. 6, rather narrow 
limits of variation $c_{1}=0,45-0,55$ are allowed; moreover, the process is also disturbed here (see Fig. 6). Outside these limits, the system is practically inoperable, as evidenced by the graphs presented in Fig. 4 and Fig. 5: in the first case $c_{1}=0,6$ (Fig. 4), i.e. the imbalance is $\Delta c=0,6-0,5=0,1$, in the second case (Fig. 5), the imbalance is the same but with opposite sign.

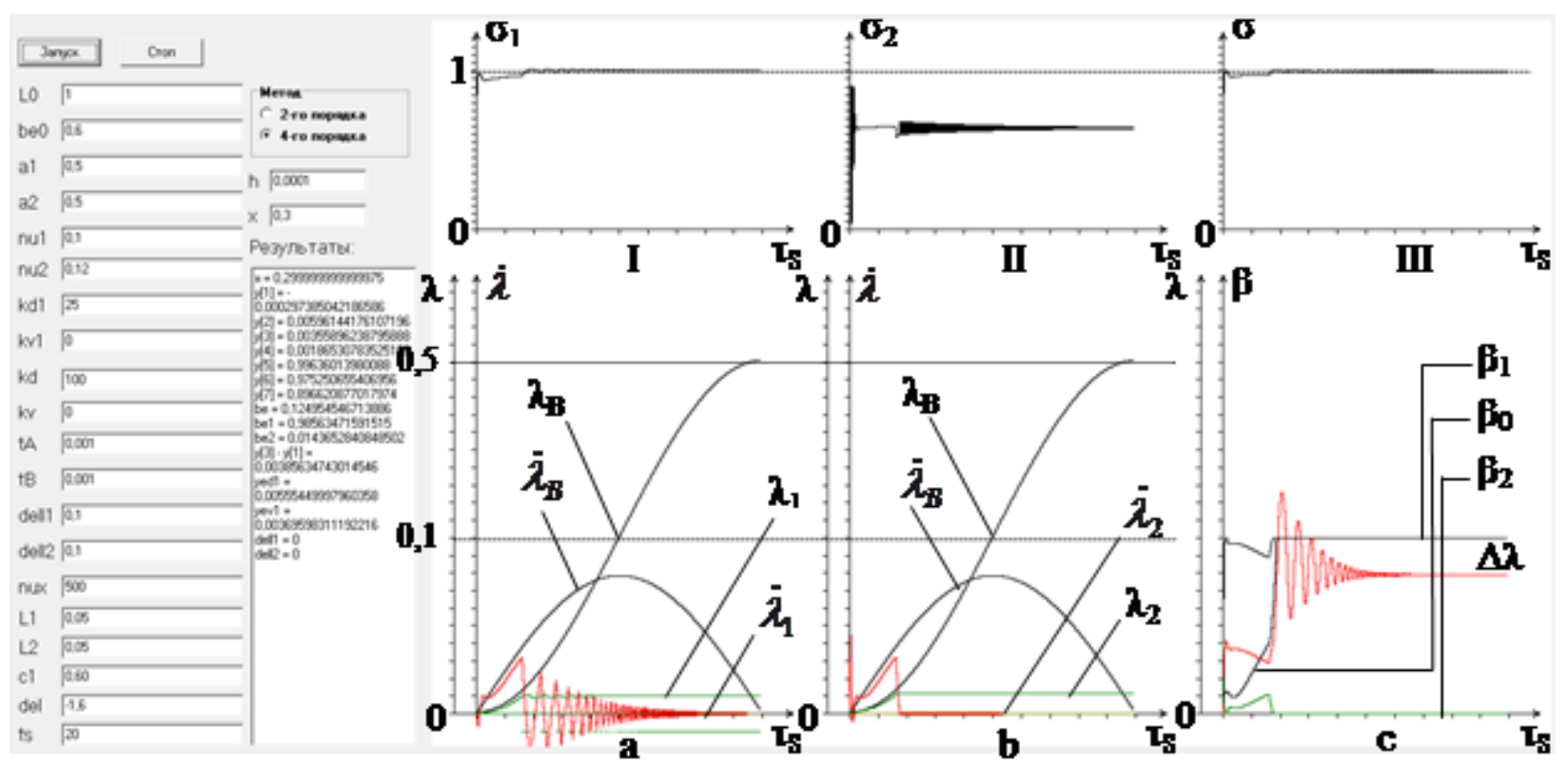

Fig. 4.

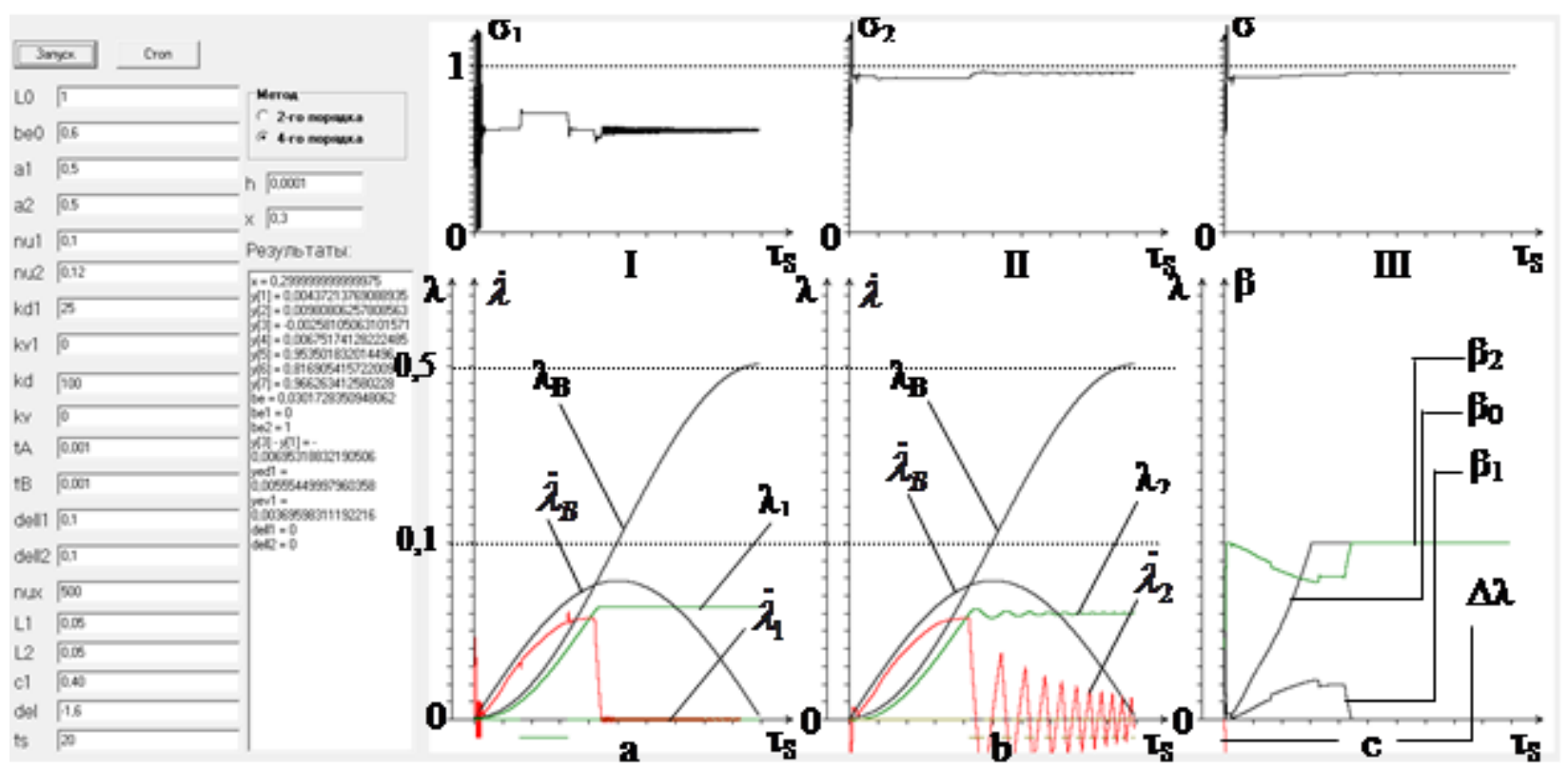

Fig. 5 . 


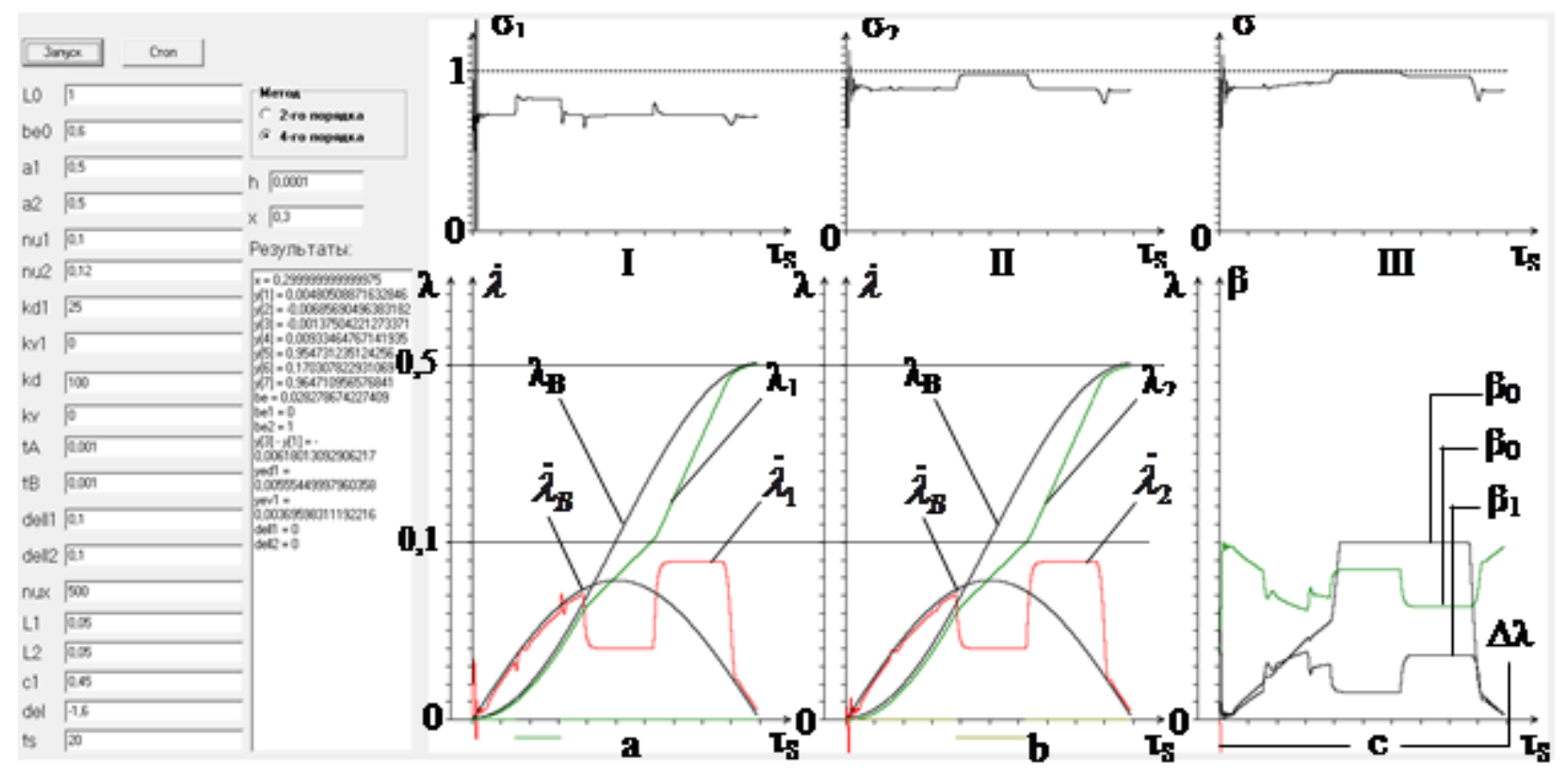

Fig. 6.

However, as mentioned above, this conclusion was obtained with the drive sizes too low. The study showed that the allowable imbalance may exceed $\Delta c=0,2$ if $\left|\chi_{L}\right|=1$, which corresponds to a nearly twofold increase in the size of the drives. If necessary, the allowable load imbalance can be increased even more at the expense of drives. This problem should be solved in accordance with the requirements for the designed system.

Option 4. The latter conclusion is also confirmed by the simulation results presented in Fig. 8 , which are obtained with a value of $\left|\chi_{L}\right|=0.2$. A significant decrease in pressure levels in all cavities indicates redundancy of the driving forces of the drives, which easily cope with the task. And from the comparison of the curves shown in Fig. $6\left(\left|\chi_{L}\right|=1.6\right)$ and in Fig. $7\left(\left|\chi_{L}\right|=\right.$ 1.8), we see a process of gradual destruction of the driving mode as the driving force of the drives decreases.

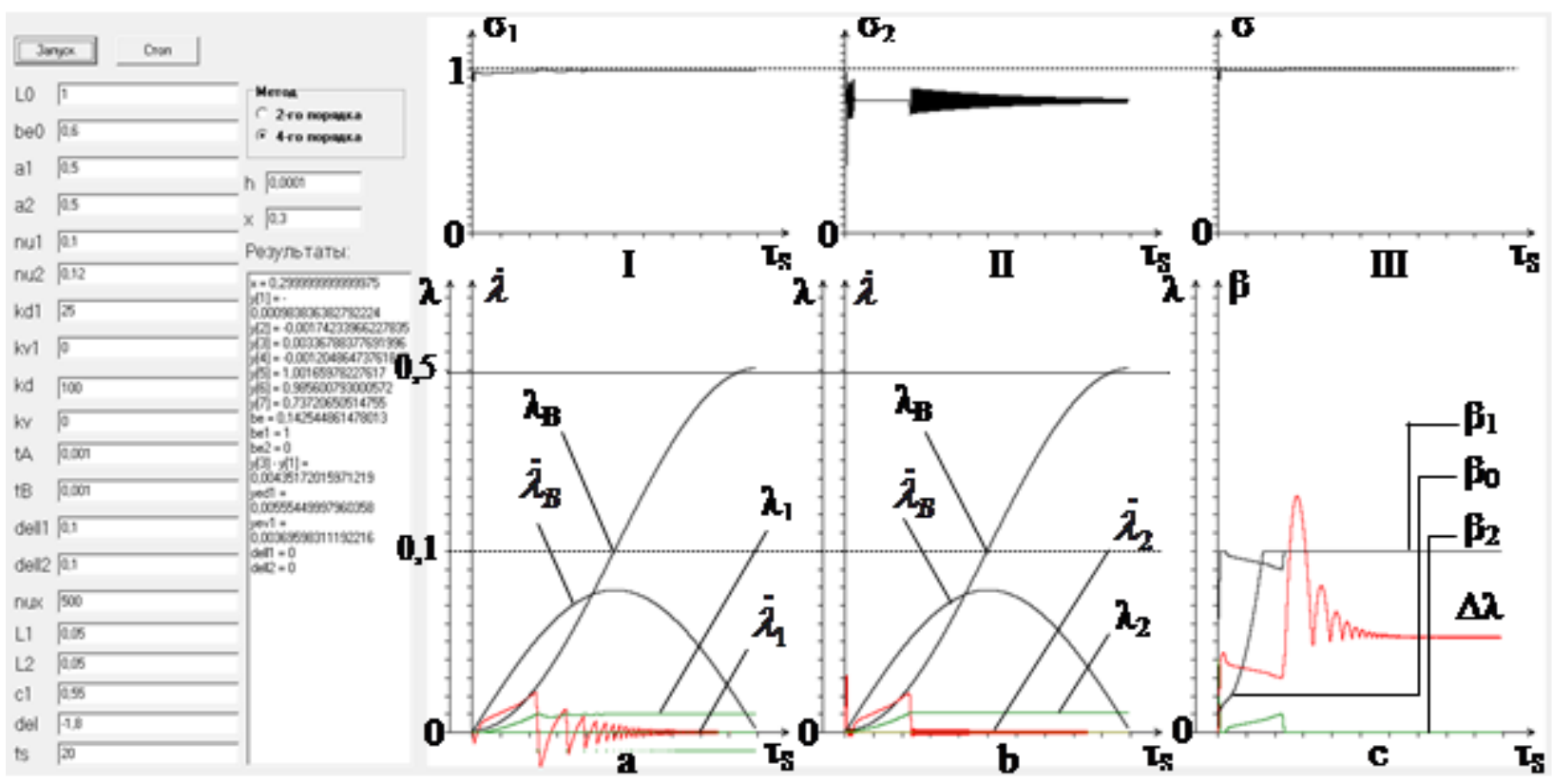


Fig. 7.

In conclusion, let us additionally consider the effect of the time factor on the process quality, which in our model is set by the parameter $\tau_{S}$, chosen in the interval 15-40. The speed of the drive directly depends on the value of this parameter. The minimum value of $\tau_{S}$, i.e. drive speed limit is constrained. The constraint condition can be expressed by the inequality $\dot{\lambda} \geq 0,95 \dot{\lambda}_{B}$ that must be satisfied when $\chi_{L 1}=\chi_{L 2}=0$ and $x=\tau_{S} / 2$. From the comparison of the simulation results presented in Fig. 9 and Fig. 10, it follows that an increase in $\tau_{S}$, (in this case from 17 to 40 ) stabilizes the process. At the same time, a further increase in $\tau_{S}$, may cause instability at the end of the turn due to a significant decrease in the speed of movement.

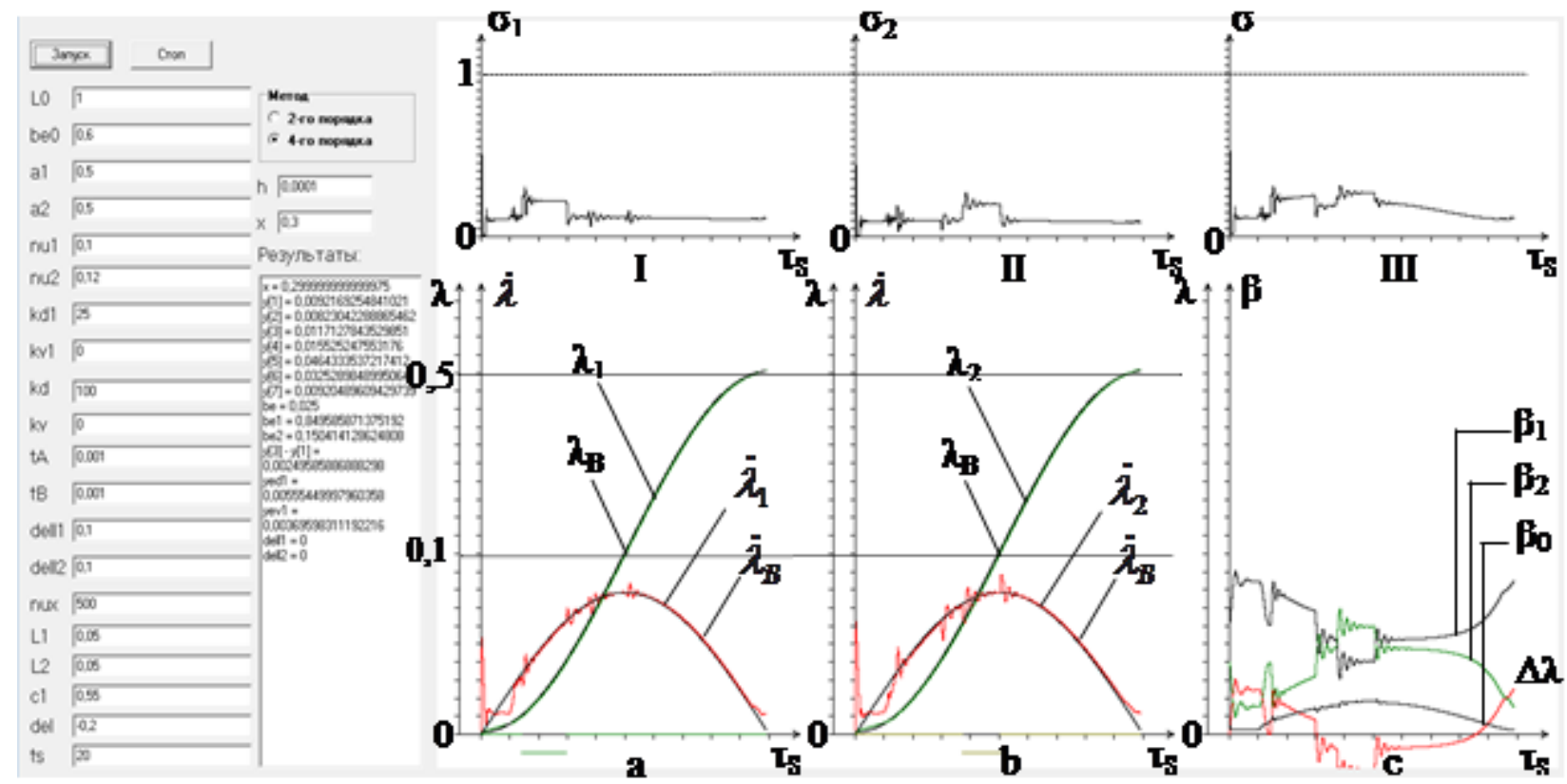

Fig. 8.

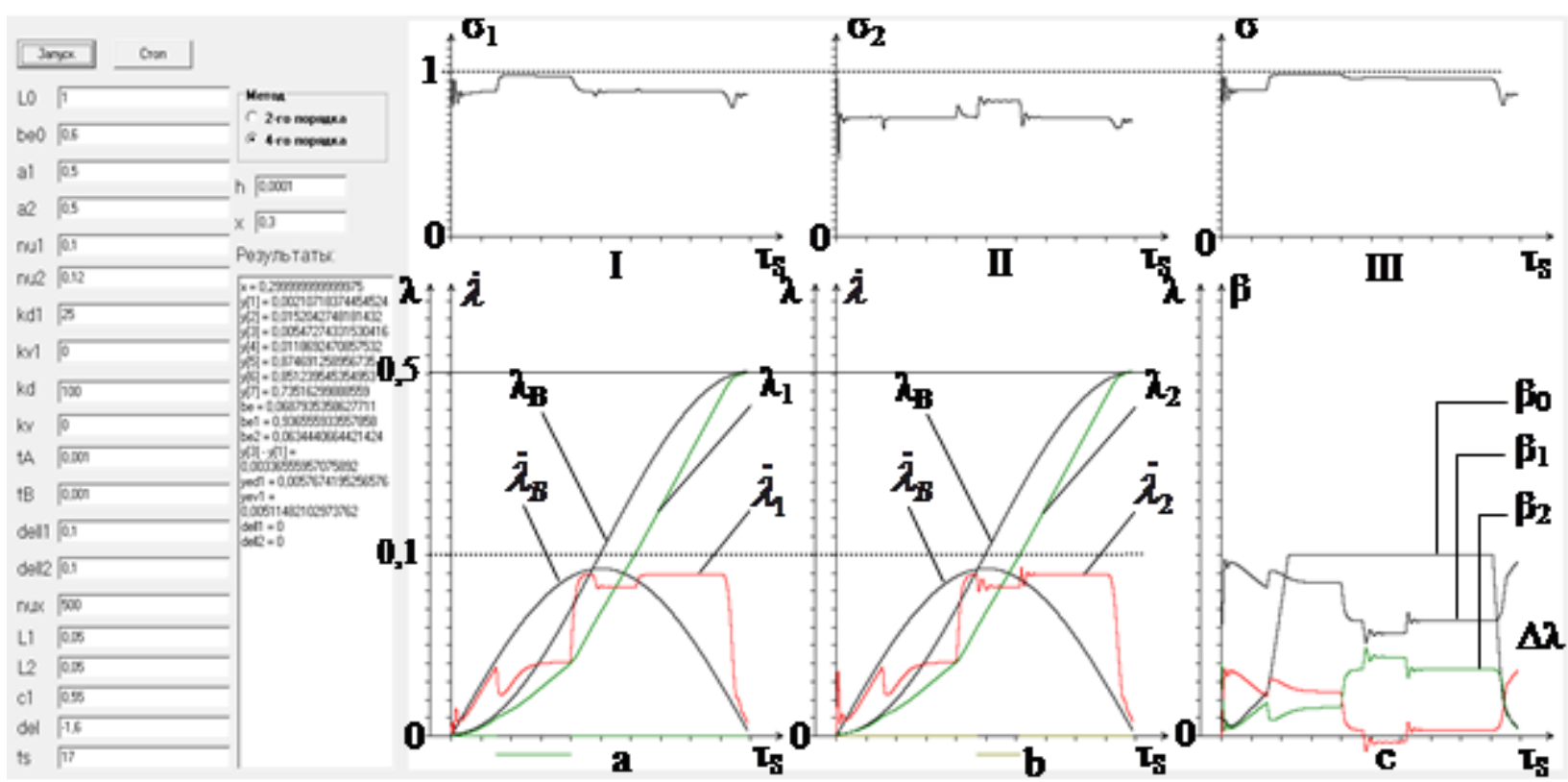

Fig. 9. 


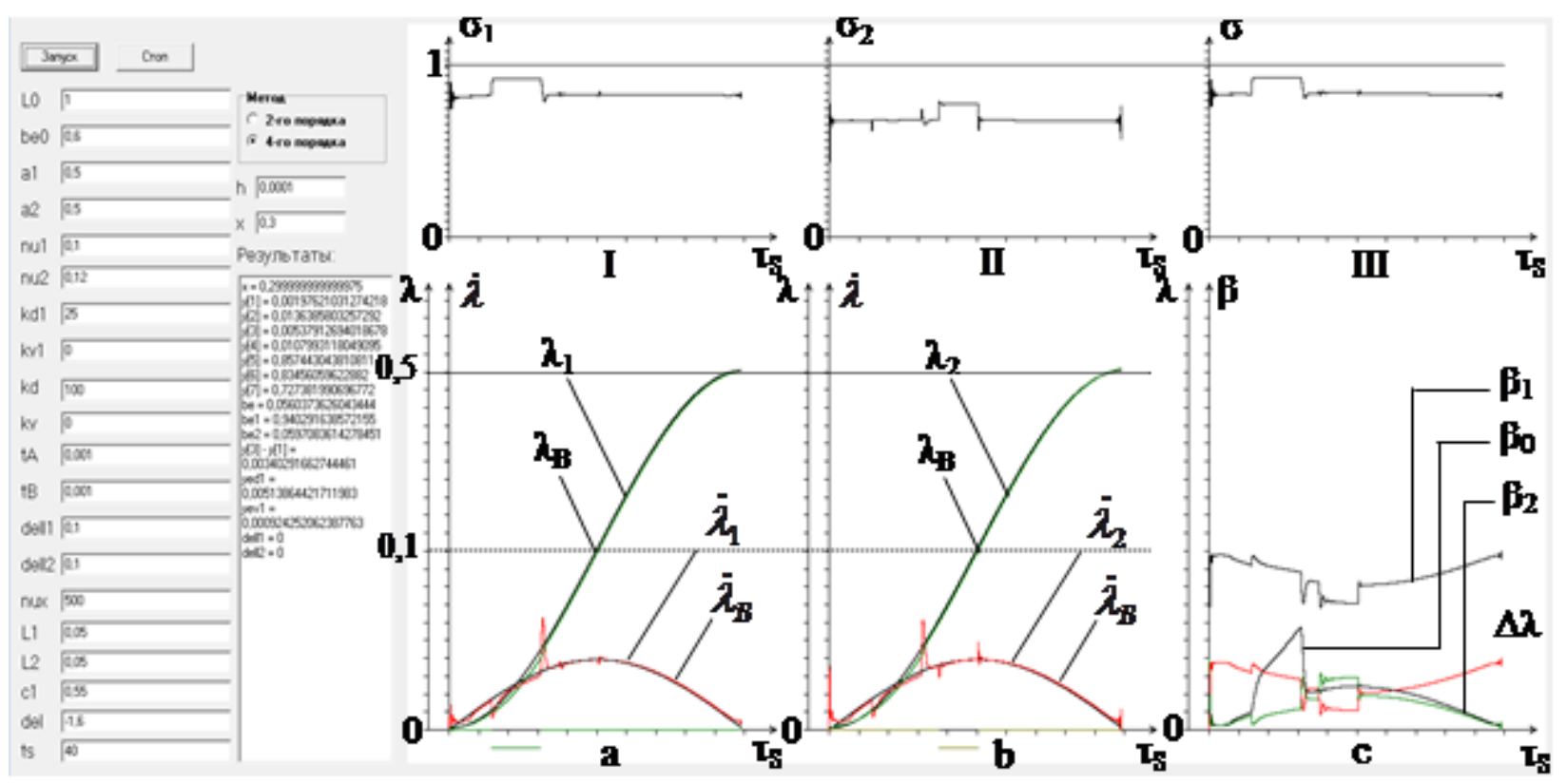

Fig. 10.

\section{Conclusion}

The paper presents an analytical interactive procedure for the formation and processing of information about the dynamics of the designed object, which can further serve as a basis for its multi-parameter, multi-criteria optimization by various methods. Information is obtained by computer simulation of the system behavior. A characteristic feature of the procedure is the visual form of presenting the results obtained in an interactive mode with a consistent and focused choice of the values of model parameters when moving from one option to another. To achieve greater generality of conclusions, the model of the system with all its characteristic indicators (criteria, constraints) is reduced to a dimensionless form.

The following problems that can be solved using the proposed procedure should be noted. First of all, this is the re-formation (narrowing) of the search space for a good solution due to the exclusion of clearly unpromising areas from it, and an assessment of the feasibility of the system with each set of parameters. In the example with the manipulator it was found, in particular, that the synchronous movement of the drives can in principle be implemented in a fairly wide range of parameters, with deviations of no more than $5 \%$ of the full stroke.

It is relatively simple to distinguish the model parameters, which have little effect on the operation of the system and, therefore, we can choose fixed values for them. Such values in the model in question include, for example, the parameter characterizing the volume of the intermediate cavity.

Visualizing simulation results is useful for formalizing complex relationships between several parameters. As an example, it is possible to point out the relationship between the unbalance of loads $\Delta \mathrm{c}$, parameters characterizing the sizes of flow sections of the hydraulic system channels, and the size of the drive. By adapting these values, it is possible to significantly increase the allowable imbalance. A certain problem arose when formalizing the estimate of the sensitivity of the manipulator to sharp, short-term relatively small power disturbances. As a result, the choice fell on the use of visual information only.

A relatively simple condition was obtained which explicitly gives an estimate of the feasibility of the required speed of drives operating in the mode of a given law of motion.

The proposed scheme for coordinated control of two parallel operating hydraulic actuators proved to be very effective and can be recommended for use in industry. The system provides a sufficiently high synchronism in the movement of the drives when the imbalance of mass loads $c_{1}\left(c_{2}\right)$ is in the range of $0.4-0.6$ and higher under the conditions of short-term power 
disturbances. The procedure for visualizing the results of the analysis and synthesis of the system simplifies preparation for finding the optimal solution and, therefore, can be recommended for use in the educational process of technical universities when studying the operation of drive systems and mechatronic complexes.

The study was financially supported by the RFBR project No. 18-29-10072.

\section{References}

1. Xiao Y., Zhu K.Y. Optimal Synchronization Control of High-Precision Motion Systems // IEEE Transactions on Industrial Electronics, 2006, Vol. 53, Issue 4, pp. 1160-1169. DOI: 10.1109/TIE.2006.878317

2. Hsieh M.-F., Tung C.-J., Yao W.-S., Wu M.-C., Liao Y.-S.. Servo design of a vertical axis drive using dual linear motors for high speed electric discharge machining // International Journal of Machine Tools and Manufacture, 2007, Vol. 47, Issues 3-4, pp. 546554. DOI: $10.1016 /$ j.ijmachtools.2006.05.011

3. Vorberg D., Schulzeb H.-H.. Linear phase-correction in synchronization: Predictions, parameter estimation, and simulations // Journal of Mathematical Psychology, 2002, Vol. 46, Issue 1, pp. 56-87. DOI: 10.1006/jmps.2001.1375

4. Dongmei Y., Qingding G., Qing H., Jiang L. Position synchronized control of dual linear motors servo system using fuzzy logic // Proceedings of the World Congress on Intelligent Control and Automation (WCICA), 2006, Vol. 2, pp. 8041-8044. DOI: 10.1109/WCICA.2006.1713539

5. Ivlev V.I., Bozrov V.M., Misyurin S.Yu., Nelyubin A.P. Parameterization of an air motor based on multiobjective optimization and decision support // Journal of Machinery Manufacture and Reliability, 2013, Vol. 42, No. 5, pp. 353-358. (ISSN 105-6188, Перевод: Выбор параметров пневмомотора на основе методов многокритериальной оптимизации и поддержки принятия решений управления). DOI: 10.3103/S1052618813050051

6. Kreinin G.V., Misyurin S.Yu. Phased synthesis of a mechatronic system // Doklady Physics, 2014, Vol. 59, Issue 11, pp. 539-543. (ISSN 1028_3358, Перевод: Поэтапный синтез мехатронной системы). DOI: $10.1134 / \mathrm{S} 102833581411010 \mathrm{X}$

7. Misyurin S.Yu., Kreinin G.V. Power optimization criteria of a mechanical unit of an automated actuator // Doklady Physics, 2015, Vol. 6o, Issue. 1, pp. 15-18. (ISSN 1028_3358Перевод: Критерии оптимизации энергетики механической системы автоматизированного привода). DOI: 10.1134/S1028335815010036

8. Misyurin S.Yu., Nelyubin A.P., Ivlev V.I. Multicriteria adaptation of robotic groups to dynamically changing conditions // Journal of Physics: Conference Series, 2017, Vol. 788, Issue 1, № статьи 012027 (Перевод: Многокритериальная адаптация робототехнических групп к динамически изменяющимся условиям). DOI: 10.1088/17426596/788/1/012027

9. Mamontov M. A. Analogichnost'. MO OF THE USSR. (Перевод: Мамонтов М.А. Аналогичность. МО СССР.) 1971. С.59.

10. Nelyubin A.P., Galkin T.P., Galaev A.A., Popov D.D., Misyurin S.Yu., Pilyugin V.V. Usage of visualization in the solution of multicriteria choice problems // Scientific Visualization, 2017, Vol. 9, Issue 5, pp. 59-70. DOI: 10.26583/sv.9.5.05

11. Manakov D.V. Data abstraction models: Sampling (parallel coordinates), filtering, clustering // Scientific Visualization, 2019, Vol. 11, Issue 1, pp. 139-176. DOI: 10.26583/sv.11.1.11 